\title{
Investigating the Continuity of Sex Offending: Evidence from the Second Philadelphia Birth Cohort
}

\author{
Franklin E. Zimring, Wesley G. Jennings, Alex R. \\ Piquero and Stephanie Hays
}

\begin{abstract}
This study uses data from the Second Philadelphia Birth Cohort to examine the natural history of sex offenders and their involvement in sexual offending through age 26. Several key findings emerged from our effort. First, only one in 10 of the 221 male and female juvenile sex offenders had a sex-related offense during the first eight years of adulthood. Second, 92 percent of all the cohort males with adult sex records had no prior juvenile sex offense. Third, a boy with no sex contacts but five or more total juvenile police contacts was more than twice as likely to commit a sex crime as an adult as a juvenile sex offender with fewer than five total police contacts. Fourth, multinomial logistic regression results demonstrated that being a juvenile sex offender did not significantly increase the likelihood for an individual being an adult sex offender, nor did the frequency of juvenile sex offending. In short, the assumptions underpinning current registration and notification laws are fraught with problems and should be re-considered.
\end{abstract}

Keywords juvenile sex offenders; registration and community notification; sex offenders

Franklin E. Zimring is Simon Professor of Law and Wolfen Distinguished Scholar at the University of California at Berkeley. His recent writing includes An American Travesty: Legal Responces to Adolescent Sexual Offending, a paperback version of which will be published by the University of Chicago Press in the Spring of 2009. Wesley G. Jennings, PhD, is an Assistant Professor in the Department of Justice Administration at the University of Louisville and holds a PhD in criminology from the University of Florida. A main area of his research is aimed at investigating questions surrounding specialization, recidivism, and continuity among sex offenders. Some of his recent publications have appeared in Justice Quarterly, Journal of Criminal Justice, Criminology and Public Policy, Journal of Research in Crime and Delinquency, and Journal of Experimental Criminology. Alex R. Piquero is Professor in the Department of Criminology \& Criminal Justice and Affiliate with the Maryland Population Research Center at the University of Maryland College Park. His interests include criminal careers, criminological theory, and quantitative research methods. He is also Executive Counselor with the American Society of Criminology and Co-Editor of the Journal of Quantitative Criminology. Stephanie Hays is at Buena Vista University, Department of Criminology. Stephanie Hays is Assistant Professor of Criminology at Buena Vista University. Correspondence to: Alex R. Piquero, University of Maryland, Department of Criminology \& Criminal Justice, 2220 LeFrak Hall, College Park, MD 20742, USA. Email: apiquero@crim.umd.edu 


\section{Introduction}

Recent estimates indicate that half a million juveniles commit a sex crime in any given year and that nearly 20 percent of all arrests for rape and a quarter of sexual abuse arrests involve juveniles as perpetrators (Weinrott, Riggan, \& Frothingham, 1997). Barbaree, Hudson, and Seto (1993) have suggested that without any treatment or intervention the average adolescent sex offender will go on to commit 380 sex crimes during their lifetime. Despite these alarming figures, juvenile sex offending has been an overlooked phenomenon in criminological research for more than half a century (Terry, 2005). For most of that period, juvenile sex offenders were also a low priority in penal legislation and the administration of juvenile justice. They were either referred to traditional counseling services (Ryan, 1998) or were not given any treatment at all based on the assumption that juvenile sexual offending is harmless (Ryan, 1999). For the past ten years, however, sex offenders-including children and teens-have become a much more important issue in penal legislation, including community notification and registration laws (Sample \& Bray, 2003, 2006; Zimring, 2004; Zimring, Piquero, \& Jennings, 2007). According to Letourneau and Miner (2005, p. 294; see also Garfinkle, 2003) these legal interventions are predicated upon a series of false assumptions including: (1) the belief that there is an epidemic of juvenile offending and juvenile sexual offending; (2) juvenile sex offenders are more similar to adult sex offenders than other delinquents; and (3) juvenile sex offenders have exceptionally high recidivism rates. Nevertheless, in this new penal environment, the lack of data on youthful sex offenders that continue their sexual offending into adulthood has become a major embarrassment. Fortunately, the youth cohort studies of the last few decades that have garnered a substantial amount of attention in the criminological literature (e.g., the Racine Birth Cohorts, the Second Philadelphia Birth Cohort) provide an opportunity to obtain good data on youthful sex offenders and their later careers.

This study reports our effort to examine data on the continuity of juvenile and young adult sex offending available in the 1958 Second Philadelphia Birth Cohort (Tracy, Wolfgang, \& Figlio, 1990; Tracy \& Kempf-Leonard, 1996) in order to examine patterns of juvenile sexual offending and the impact of a juvenile police contact for a sex offense on the likelihood of sex offending in adulthood. First, we offer a brief review of the prior research investigating juvenile sex recidivism in general, and then provide a discussion of the few recent studies exploring the link between juvenile and adult sex offending in particular. Next, we demonstrate a profile of the patterns of juvenile sex offending and sex offenders, which is followed with an examination of the data on adult sexual offending for the total sample and for the group within the sample that had sex offense police contacts during their juvenile careers. Lastly, we conclude by investigating the ability to predict adult sex offending based on a history of juvenile sex offending and the frequency of juvenile sex offending. The general pattern we find is that juveniles with sexually based police contacts have a high 
volume of non-sex contacts and a low rate of sexual recidivism during their juvenile careers, and an even lower probability for sexual offending during young adulthood. Policy implications for the findings presented in this study are also discussed.

\section{Prior Research on the Continuity of Sex Offending}

Although there exists a sizable literature linking juvenile to adult patterns of offending (Piquero, Farrington, \& Blumstein, 2003) and a growing amount of research has recently begun to examine juvenile sex offender recidivism (Abel, Mittelman, \& Becker, 1985; Becker, Cunningham-Rathner, \& Kaplan, 1986; Groth, Longo, \& McFadin, 1982; Miner, 2002; Miner, Siekert, \& Ackland, 1997; Milloy, 1994; Meloy, 2005; Rasmussen, 1999; Sample \& Bray, 2006) and comparing juvenile sex offenders with juvenile non-sex offenders (Van Wijk et al., 2006), there is only a scant amount of research investigating the possible link between juvenile and adult sex offending (Burton, 2000).

Although Doren's (1998) early review of the sex offender recidivism literature suggested that sex offenders remained at continued risk for sex recidivism for decades, the studies conducted in the 1980s were usually cross-sectional and retrospective studies of adult sex offenders (Abel et al., 1985; Becker et al., 1986; Groth et al., 1982). For example, Sipe, Jensen, and Everett (1998) revealed a sex offender continuity rate of 9.7 percent for 164 juvenile sex offenders. These researchers also found that having a juvenile sex arrest was significantly related to having an adult sex arrest when compared with other juvenile offenders, but the sample was composed of only nonviolent sex offenders; therefore, these results are unlikely to be generalizable to other samples of juvenile sex offenders. In contrast, Rubinstein, Yeager, Goodstein, and Lewis (1993) reported a 37 percent recidivism rate of sex offending among 19 offenders who began their sexual offending in adolescence; however, this is an extremely small sample, and other researchers have noted that this sample was especially violent and these results are unlikely to be representative of juvenile sex offenders either (Sipe et al., 1998). Relying on conviction data, Hagan and Gust-Brey (1999) reported an 8 percent to 16 percent sex recidivism rate among a sample of adolescent rapists based upon a 5- and 10-year follow-up, respectively. Thus, according to a review of the minimal sex offending continuity literature provided by Worling and Curwen (2000; see also Langström, 2002; Langström \& Grann, 2000), these earlier studies (with the exception of Rubinstein et al., 1993) indicate that juvenile sex offender recidivism rates lie between 3 percent and 14 percent with general recidivism rates between 14 percent and 60 percent after six years of follow-up.

More recently, Nisbet, Wilson, and Smallbone (2004) followed a sample of 303 adolescent male sex offenders in New South Wales, Australia for an average of a little over seven years post adjudication for a sex offense. Their results suggested that while 25 percent of the males were reconvicted for a sex offense 
in their juvenile careers, only 9 percent were rearrested and 5 percent were reconvicted for a sex offense in adulthood. Similarly, based on a ten year follow-up of incarcerated male juvenile sex offenders that participated in two sex offender treatment programs in Virginia, Waite et al. (2005) reported a sex recidivism rate of less than 5 percent regardless of program intensity and a nonsex recidivism rate near 40 percent. In another comprehensive study investigating the continuity of juvenile sex offending into adulthood, Vandiver (2006) assessed the sex recidivism rates of 300 registered male sex offenders in Texas for 3-6 years after having reached adulthood. Vandiver's results indicated that only 13 of the 300 (4.3 percent) juvenile male sex offenders recidivated as an adult for a sex offense. This finding highlights the virtual absence of sex offending continuity; by contrast, it is important to note that almost half of these juvenile sex offenders did in fact recidivate as an adult for a non-sex offense.

Zimring et al. (2007) provided the most recent study to date exploring sex offender continuity and improved upon prior research by utilizing a large community-based sample of males and females from Racine, Wisconsin. Through a series of bivariate analyses, Zimring et al. indicated that there was little to no association between being a juvenile sex offender and having continued this behavior into adulthood for either male or female youth. More specifically, once they estimated the effects in a multivariate context, their results demonstrated that having a juvenile sex offense did not significantly predict an individual's likelihood for being an adult sex offender. Furthermore, Zimring et al. found a robust significant effect for the length of a juvenile's record for predicting adult sex offender status; in other words, offense frequency rather than juvenile sex offending was the better predictor of adult sex offending.

\section{Current Focus}

Overall, one finding that has emerged from this small line of research is the relatively high rates of non-sexual adult offending for the juvenile sex offenders. It appears then, that there is little power for a juvenile sex offense for predicting an adult sex offense, and that juvenile sex offenders tend not to specialize (Miethe, Olson, \& Mitchell, 2006). Still, this and other research assessing the potential link between juvenile and adult sex offending remains limited such that reaching any firm conclusions is premature (Burton, 2000). For example, with the exception of a few of the most recent studies (Nisbet et al., 2004; Vandiver, 2006; Waite et al., 2005; Zimring et al., 2007), almost all of the prior studies dealing with juvenile sex offenders have relied on small clinical or incarcerated samples with little generalizability. Additionally, Nisbet et al. (2004), Waite et al. (2005), and Vandiver's (2006) research (similar to most prior studies as well) utilized a sample of male juvenile sex offenders, limiting generalizabilty. Comparatively, Zimring et al.'s (2007) study is perhaps the most comprehensive research in the criminological literature exploring the continuity of juvenile sex offending into adulthood using a community-based sample of 
males and females (Miner, 2007), but uses a racially homogenous (mainly White) sample from a small midwestern city, with low evidence of serious criminality generally, and non-minor sex offending in particular.

Attending to the issues mentioned above and following the research design of Zimring et al., this study investigated the ability of a juvenile sex offense to predict adult sex offender recidivism among males and females from the Second Philadelphia Birth Cohort (Tracy et al., 1990; Tracy \& Kempf-Leonard, 1996). A direct replication and extension of the Zimring et al. study with the Philadelphia data is especially important because the Philadelphia data comprise a large sample of individuals who "grew up" during a period of increasing crime rates in a rather high crime social context, are much more racially heterogeneous (including both Whites and Blacks), are from a major urban city, and have extensive evidence of serious criminal activity, all features that depart significantly from much of the prior sex offender research generally, and the Racine data used by Zimring et al. in particular.

\section{Methodology}

\section{Data}

A review of research on juvenile sex offenders found several studies of groups of such offenders (Zimring, 2004) but no data from the series of birth cohort studies (with the exception of Zimring et al., 2007), such as those from Philadelphia that followed large samples of city residents born in the same year through adolescence and into young adulthood (Wolfgang, Figlio, \& Sellin, 1972; Wolfgang, Thornberry, \& Figlio, 1987). We use data from the 1958 Second Philadelphia Birth Cohort-13,160 boys and 14,000 girls-because the sample was quite large and was followed up through eight years post age 18 or through age 26. The main focus was on subjects with police contacts for sex offenses during the years prior to age 18, which was a total of 204 boys and 17 girls. The fact that the number of juveniles with police contacts for sex offenses was small is, in itself, an important observation because of the perception that such offenders are rampant (see Letourneau \& Miner, 2005). Additionally, we also recognize that some readers may question the inclusion of the small number of female (sex offenders) in the sample as appropriate, and thus favor their exclusion. However, it is important to retain the females not only because they have been neglected in extant criminological research generally, but their exclusion in the sex offender research area has been specifically noted. The fact that there are so few female sex offenders, especially sex recidivists, is an important finding in and of itself, and their exclusion, because of the small number of cases, would likely not have had altered any of the statistical or substantive findings and conclusions. Thus, they are retained in the current study.

The primary data on criminal justice involvement in the Philadelphia studies is police record data, which is the first official record of criminal activity and of 
course the largest number of official offenses will be at the police contact level. Data were available for all juvenile police contacts prior to age 18 and for all adult offenses during the eight years following age 18. Specifically, according to Tracy and Kempf-Leonard (1996, p. 65), "police rap sheets and investigation reports were provided by the Juvenile Aid Division of the Philadelphia Police Department to characterize police encounters experienced by the Cohort before age 18." Further, "[t]he Municipal and Court of Common Pleas of Philadelphia served as data sources for offenses committed by the cohort after reaching the legislatively imposed adult status of age 18. Court files included police reports, so data on adult crime are comparable to that for delinquency. The exception, of course, is that no official "remedial" report exists for adults who encountered police, but who were not arrested. Adult criminal history data were available through December 31, 1984, or through age 26 for all cohort members" (Tracy \& Kempf-Leonard, 1996, p. 65). A more general overview of the offending careers of the Cohort may be found elsewhere (Tracy et al., 1990; Tracy \& Kempf-Leonard, 1996).

We recognize that there are strengths and weaknesses from using either official (police contact, arrest, conviction) or self-report data to measure criminal behavior (Hindelang, Hirschi, \& Weis, 1981; Thornberry \& Krohn, 2003). We chose to use the official police records that had true crime codes (i.e., status offenses, traffic offenses, city ordinance violations, etc. were removed) because they are (1) a more accurate official measure of "true" offending and they are (2) closer in time to the actual criminal act than self-reported offending. Overall, the analyses presented in the following section were based on the total sample of 13,160 males and 14,000 females, with additional analyses specifically investigating the link between juvenile and adult sex offending among the 221 juvenile sex offenders.

\section{Analytic Procedure}

Similar to the methodological design and statistical techniques adopted by Zimring et al.'s study, the analysis described below progressed in several stages. First, we began our analysis by investigating the prevalence and frequency of juvenile sex and non-sex offending among males and females. Second, we examined the prevalence and frequency of adult sex and non-sex offending and discuss these findings with attention toward the continuity of sex offending from adolescence to adulthood. Third, we considered the types of sex offenses that characterized the juvenile careers of those youth who had a sexually based police contact prior to age 18 compared with the adult sex offenders who did not have an officially recorded juvenile sex offense in their criminal career. This stage of the analysis also involved a series of bivariate comparisons exploring the nature of sex and non-sex recidivism, specialization, and any identifiable features of juvenile sex offenders. Last, we estimated two multinomial logistic regression models to determine the ability to predict an 
individual's adult criminal record (i.e., no-record, non-sex offending, sex and non-sex offending, or sex-only offending) with a juvenile sex offense (yes/no) and/or based on the frequency of a juvenile's sex offending.

\section{Results}

\section{Juvenile Sex Offending in Philadelphia}

Fewer than 30 percent of the Philadelphia boys had a police record by age 18 and a total of 1.6 percent had sex offense records. The girls had just above a quarter of the police contact rate, 7.4 percent versus 28 percent, but only 17 of 14,000 girls-slightly more than one in every thousand-had an official juvenile sex offense contact. There were no indications that female sex offense contacts during the juvenile period were related to future sex recidivism either in their juvenile career or into young adulthood. Only two of the 17 females with a juvenile sex contact had a second such contact during the juvenile period, and none of the 17 girls had any sex offenses during the eight years following age 18 . Regarding the males, a sex offense contact was the only juvenile offense for less than a fifth of the males (see Figure 1), and the median number of total juvenile contacts was six ( $M=7.4$ contacts).

So, the question is: what distinguishes these juvenile sex offenders from the juvenile non-sex offenders? The juveniles with a sex contact had three times the median rate of total juvenile contacts than the juvenile offenders without a sex contact. A little more than half of the juveniles with any sex contacts had the five contacts that Wolfgang et al. (1972) regarded as the threshold for chronic offending, but very few of the police contacts among this group were for sex offenses. Approximately 85 percent of the juvenile sex contact group had only one such sex contact and 80 percent of all the police contacts for the group did not involve sex offenses. There were however, race and socioeconomic differences

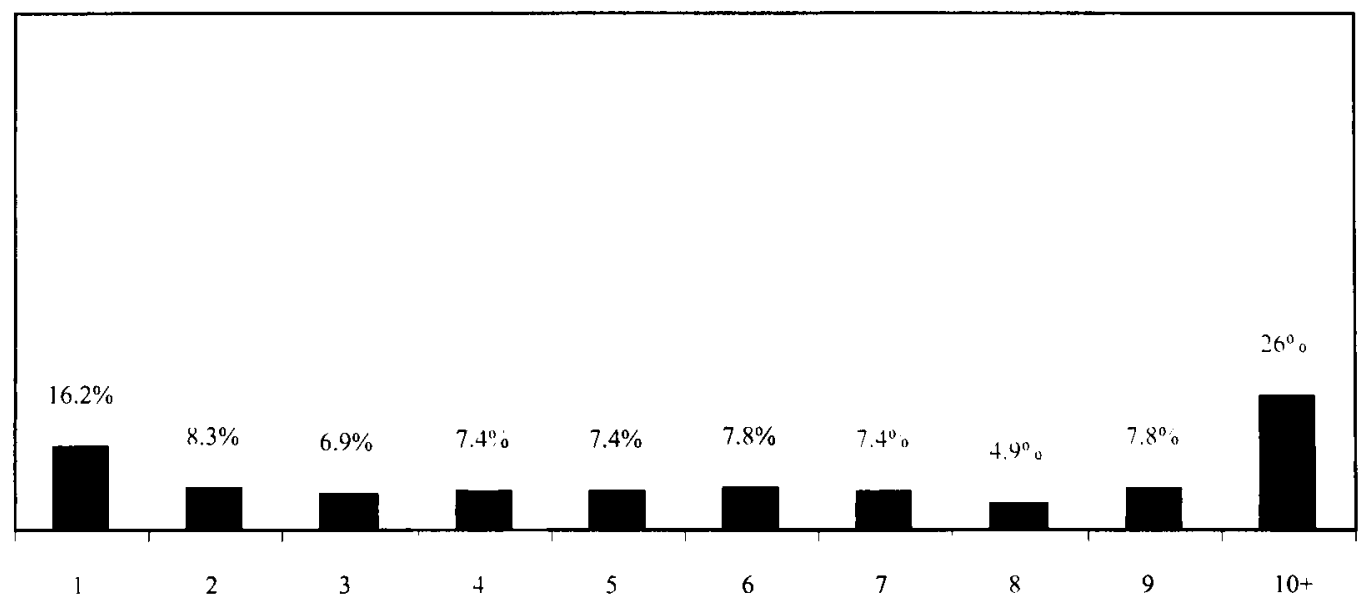

Figure 1 Total juvenile contacts for males with sex offense contacts. 
between the juvenile sex offenders and the juvenile non-sex offenders. The juvenile sex offenders were more likely to be non-White $\left(\%^{2}=15.70, p<.001\right)$ and from low socioeconomic status households $\left(\chi^{2}=21.67 ; p<.001\right)$.

Nevertheless, the primary characteristic of the male juvenile sex contact group in Philadelphia was the extraordinary frequency of both total and nonsexual police contacts but single sex contact histories. What set these boys apart from other juvenile males with police records was a differential probability to be contacted several times for non-sex offenses prior to reaching age 18 and being non-White and from a low SES background. The juvenile sex offenders appeared to be the very opposite of specialists-typically one-time sex offenders but many time offenders for everything else. As Zimring et al. (2007, p. 527) have suggested, sex offenders just tend to "roll the dice more often."

\section{Adult Sex Offending and Investigating Sex Offending Continuity in Philadelphia}

In order to more effectively answer the continuity question surrounding sex offending, it was important to first examine the sex and non-sex offending patterns of the adults in Philadelphia compared with the juvenile rates for these offenses. Among the males, 23.2 percent had an adult record, a smaller figure than was found in the juvenile years. Further, 2.4 percent of all the males had an adult record for a sexually based offense, which was a larger proportion of the male population ( 2.4 percent versus 1.6 percent) and more than twice the proportion of males with any police record (10.1 percent versus 4.7 percent) than was found among the same males as juveniles. The prevalence of sex offending was higher after age 18 and the share of all offenses that involved a sex offense increased substantially for the males after turning age 18. Comparatively, 3.8 percent of the females had an adult record, but the prevalence of sex offending was only three-tenths of one percent. While this was a larger proportion than was found among the juvenile females, the eight years of exposure could likely account for much of the difference.

The most striking feature of the Philadelphia data was the lack of overlap between juvenile sex offending and adult sex offending. For the girls, none of the juvenile sex offender contact group $(n=17)$ could be found among the group who had a sexually based offense past the age of 18 . If one were estimating the impact of a registration system from these data, the false positive rate among the juvenile females for adult sex offending would be 100 percent and similarly, 100 percent of the adult female sex offenders would not have been part of the registry in the first place. Therefore, it is arithmetically impossible for a prediction system to have had a poorer performance than the outcome for Philadelphia females.

For the males, the predictions of adult sexual offending were also quite poor if not in the zero range. One in ten of the males with juvenile sex offense contacts had an adult sex offense record in Philadelphia in the follow-up period 
after age 18. Furthermore, the 53 sex offenses attributed to this group were 7.8 percent of the total adult sex offenses attributable to the cohort males. So, using the juvenile sex records to predict who would become an adult sex offender in this scenario produced a false positive rate of 90 percent for the young men targeted while it also missed 92.2 percent of all the adult male sex offenders. Both the false positive and false negative rates were 90 percent or greater, a discouraging record for predictions of dangerousness over an eightyear period in young adulthood.

Overall, the lack of association between juvenile sex offending and adult sex offending was not simply a function of the low base expectancy rate of adult sex offenses. One possible explanation was that the juvenile sex offenders were spectacularly non-specialized. The 204 male juvenile sex offenders were responsible for a total of 446 adult offenses, which were only 5.6 percent of the total adult sex and non-sex offenses for the males. Juvenile sex offenders were not significantly more likely than other adults with a record to have had an adult offense that involved sex.

The results of an additional effort to explore the possible differences in the types of sex offenses committed by those who do continue their sex offending into adulthood versus those that did not begin their sex offending careers until adulthood are presented in Table 1 . The main findings were that rape and indecent assault were the most prevalent sex offenses for both juvenile and adult sex offenders as well as for the adult-only sex offenders (although corrupting the morals of a minor was the second most prevalent sex offense type among the adult-only sex offenders). The remaining categories of sex offenses were relatively similar; therefore, the only significant mean differences detected between juvenile and adult sex offenders and adult-only sex offenders were that the males who began their sex offending as a juvenile and continued their sex offending behavior into

Table 1 Adult sex offense type by former juvenile sex offenders and adult-only sex offenders

\begin{tabular}{lclr}
\hline $\begin{array}{l}\text { Juvenile sex offenders with } \\
\text { an adult sex offense }\end{array}$ & $\%$ & Adult-only sex offenders & $\%$ \\
\cline { 1 - 2 } Indecent assault & $67 \%^{*}$ & Forcible rape & $46 \%$ \\
Forcible rape & $62 \%$ & Corrupting morals of a minor & $43 \%$ \\
Corrupting morals of a minor & $38 \%$ & Indecent assault & $42 \%$ \\
Deviate involuntary sex & $24 \%$ & Public indecency & $15 \%^{*}$ \\
Attempted rape & $24 \%$ & Attempted rape & $14 \%$ \\
Incest & $5 \%{ }^{*}$ & Deviate involuntary & $12 \%$ \\
Prostitution/solicitation & $0 \%$ & Prostitution/solicitation & $4 \%$ \\
Statutory rape & $0 \%$ & Statutory rape & $4 \%$ \\
Deviate voluntary sex & $0 \%$ & Deviate voluntary sex & $2 \%$ \\
Pandering & $0 \%$ & Pandering & $0.3 \%$ \\
Public Indecency & $0 \%$ & Incest & $0.3 \%$ \\
\hline
\end{tabular}

${ }^{*} p<.05$. 
adulthood were significantly more likely to have committed an indecent assault $(t=-2.181 ; p<.05)$ or incest $(t=-2.510 ; p<.05)$ in adulthood compared with the adult-only sex offenders. The adult-only sex offenders also were significantly more likely to have committed a public indecency offense $(t=1.944 ; p<.05)$.

\section{Continuing the Search for Prediction}

There were some indications in the timing of the sex offenses for juveniles with an adult sex record that any sexual offending in adulthood by the former juvenile sex offenders began early if at all. A majority of all of the adult sex careers started in the first two years after age 18 , and 81 percent of all adult sex careers were initiated in the first four years. Thus, the total number of new sex offenders in the four years after age 21 was 2 percent of the juveniles with sex records. If that approximate decline in new cases persisted in future five-year periods (e.g., $17,4,2,1, .5$-assuming 50 percent drop-off-or $17,4,1, .25$-assuming the 4-to1 drop pattern continues), the best guess of sex offending for male adulthood would be between 12 percent and 14 percent lifetime.

While a 10 percent continuity rate for sex offending was not large, it was still better than the 2.4 percent prevalence of adult sex offending for all the males. There were two reasons why it is important to further examine what elements of a juvenile record might predict adult sex offending. The first reason was to determine whether some combination of prior record might make for a much better eight-year risk prediction than the 10 percent found for all juvenile sex offenders. The second reason to test for different predictions was to see which of the two distinguishing characteristics of juvenile sex offenders-a high volume of juvenile contacts or a history of juvenile sex offending-was the better predictor of an adult sex record.

The pattern displayed in Figure 2 was clear. Only one category of juvenile males had a lower rate of adult sex offending than the overall male mean of 2.4 percent: males with no juvenile contacts had a 1.4 percent rate of adult sex offenses. At the high end, no combination of prior sex offending and prior contacts had a much larger true positive rate than 15.6 percent. Juveniles with

Juveniles with $>5$ contacts, at least one for sex

Juveniles with $>5$ contacts, none for sex

Juveniles with $<5$ contacts, at least 1 for sex

Juveniles with $\leftrightharpoons 5$ contacts, none for sex

Juveniles with no contacts

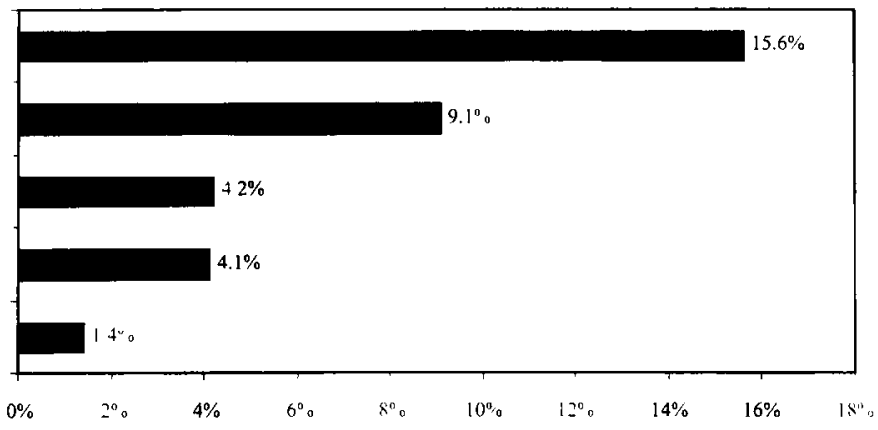

Figure 2 Distinguishing adult sex offenders based on juvenile record. 
more than five total juvenile police contacts (over half of total juvenile sex offenders) who also had a juvenile sex contact had a 15.6 percent rate of sex offending in the eight years following age 18. The next highest sex offending group in adulthood were the males with no juvenile sex offenses but five or more total juvenile police contacts ( 9.1 percent). Non-sex offending juveniles with five contacts ( 9.1 percent) were more than twice as likely as juvenile sex offenders without long general records (4.2 percent) to end up as adult sex offenders. And the juveniles with fewer than five contacts including a sex offense (4.2 percent) were no more likely to have an adult sex record than juveniles with fewer than five contacts and no sex offenses ( 4.1 percent).

Results from an analysis of variance indicated that while having a juvenile record was significantly associated with an adult sex record $(F(4 ; 13,155)=67.468$, $p<.001$ ), post hoc tests suggested that neither the juveniles with less than five contacts and at least one sex contact (4.2 percent) significantly differed from juveniles with less than five contacts and no juvenile sex contact ( 4.1 percent). More importantly, significant mean differences were not detected between the high contact juvenile sex offender group (i.e., five or more contacts; 15.6 percent) and their non-sex high contact counterparts ( 9.1 percent). This illustrated that although the rate of adult sex contact may differ slightly in magnitude, there was no significant difference in increasing the ability to gauge adult sex offending by a boy having exhibited juvenile sex offending behavior, holding their high juvenile offending frequency constant. ${ }^{1}$

The bivariate results discussed earlier provided a basis for investigating the possible association or lack of association between juvenile and adult sex offending; however, it was necessary to further evaluate this continuity assumption within the context of a multivarite model as recently presented by Zimring et al. (2007). Specifically, we estimate two multinomial logistic regression models, where the outcome variable, adult record type, comprises four categories (adult contacts-no sex contact, adult contacts-sex and other contact, and adult contacts-sex only contact; omitted reference category no adult contacts), and four independent variables: sex (male), race (non-White), juvenile sex offending (a: no/yes, b: frequency), and juvenile police contacts.

The results from the first multinomial logistic regression model (see Table 2) supported the expectation on the nature of the relationship between juvenile and adult sex offending. Consistent with Zimring et al., being male and nonWhite significantly increased the odds of an individual being an adult offender across all adult record types (i.e., non-sex offender, sex and non-sex offender,

1. In accordance with guidelines regarding the appropriate post hoc procedures (see Field, 2005), we relied on both Dunnett's $C$ and Games-Howell post hoc tests because of the unequal sizes of the groups and because the results from a Levene test indicated that the assumption of equal population variances (i.e., homogeneity of variances) was violated. The results from these post-hoc tests indicated that the first and second groups shown in Figure 2 (i.e., the 9.1 percent and 15.6 percent groups) were not significantly different from one another; the 15.6 percent group was significantly different from the other three groups (4.2 percent, 4.1 percent, and 1.4 percent); and the 9.1 percent group was significantly different from the same three groups (4.2 percent, 4.1 percent, and 1.4 percent). 
Table 2 Multinomial logistic regression predicting adult offender status with a history of juvenile sex offending ${ }^{a}$

\begin{tabular}{|c|c|c|c|c|c|c|}
\hline \multirow[b]{2}{*}{ Variables } & \multicolumn{2}{|c|}{$\begin{array}{l}\text { Adult contacts } \\
\text { (no sex contacts) }\end{array}$} & \multicolumn{2}{|c|}{$\begin{array}{l}\text { Adult contacts (sex } \\
\text { and other contacts) }\end{array}$} & \multicolumn{2}{|c|}{$\begin{array}{c}\text { Adult contacts } \\
\text { (sex-only contacts) }\end{array}$} \\
\hline & Wald & Odds & Wald & Odds & Wald & Odds \\
\hline Male & $1150.89^{* * *}$ & 5.90 & $77.17^{\star * *}$ & 11.02 & $66.50^{* * *}$ & 5.84 \\
\hline Non-White & $181.03^{* * *}$ & 1.77 & $58.08^{* * *}$ & 4.98 & $29.83^{* * *}$ & 2.60 \\
\hline Juvenile sex offender (yes/no) & 0.45 & 0.89 & 2.81 & 1.76 & 0.05 & 0.91 \\
\hline $\begin{array}{l}\text { Juvenile police contacts } \\
-2 \text { log likelihood }=1,226.231 \\
\text { Model } \chi^{2}=3,906.810^{* * *} \\
\text { Nagelkerke } R^{2}=.228 \\
N=27,160\end{array}$ & $661.91^{\star \star *}$ & 1.37 & $238.54^{\star \star \star}$ & 1.39 & $259.86^{\star \star \star}$ & 1.41 \\
\hline
\end{tabular}

${ }^{a}$ Cohort members with no adult offenses served as the reference category for the dependent variable (i.e., adult record type).

$p<.001^{\star \star \star}$

and sex-only offender), with non-adult offenders left out as the reference category. More importantly, the results indicated that having a juvenile sex offense (no/yes) contributed virtually nothing insofar as predicting membership in any adult offender group, and particularly failing to predict the odds of being an adult sex offender. In fact, the frequency of a juvenile's police contacts was the better predictor of being an adult sex offender.

The results from the second multinomial logistic regression model further confirmed the findings of the previous model. The only difference between this model and the former model was that in the first model a dichotomous variable was used for being a juvenile sex offender (no/yes) and this second model incorporated the frequency of a juvenile's sex offending. According to the results presented in Table 3, once again, being male and non-White significantly increased the odds of being an adult offender (i.e., non-sex offender, sex and non-sex offender, and sex-only offender), and in this case, the frequency of juvenile sex offending did relatively nothing for predicting being an adult sex offender either. The frequency of a juvenile's police contacts was once again the better predictor of being an adult sex offender.

\section{Discussion}

This study sought to examine the natural history of sex offenders and sex offending using data from the Second Philadelphia Birth Cohort. In addition to providing baseline data on juvenile and early adult sex offending patterns, we also sought to examine the linkage between juvenile and adult sex offending as well as evaluating the predictive power of juvenile sex offending on adult sex offending. In 
Table 3 Multinomial logistic regression predicting adult offender status with juvenile sex offending frequency ${ }^{a}$

\begin{tabular}{|c|c|c|c|c|c|c|}
\hline \multirow[b]{2}{*}{ Variables } & \multicolumn{2}{|c|}{$\begin{array}{l}\text { Adult contacts } \\
\text { (no sex contacts) }\end{array}$} & \multicolumn{2}{|c|}{$\begin{array}{l}\text { Adult contacts } \\
\text { (sex and other } \\
\text { contacts) }\end{array}$} & \multicolumn{2}{|c|}{$\begin{array}{l}\text { Adult contacts } \\
\text { (sex-only } \\
\text { contacts) }\end{array}$} \\
\hline & Wald & Odds & Wald & Odds & Wald & Odds \\
\hline Male & $1150.90^{\star \star \star}$ & 5.90 & $77.74^{\star \star \star *}$ & 11.10 & $63.39^{* * *}$ & 5.84 \\
\hline Non-White & $181.28^{\star \star \star}$ & 1.77 & $58.85^{\star \star \star}$ & 5.03 & $29.79^{* * *}$ & 2.60 \\
\hline Juvenile sex offending (yes/no) & 2.51 & 0.88 & 0.03 & 1.03 & 0.03 & 0.98 \\
\hline $\begin{array}{l}\text { Juvenile police contacts } \\
-2 \log \text { likelihood }=1,322.96 \\
\text { Model } \chi^{2}=3,906.08^{\star \star *} \\
\text { Nagelkerke } R^{2}=.228 \\
N=27,160\end{array}$ & $681.59^{* * *}$ & 1.37 & $270.39^{* \star \star}$ & 1.41 & $258.13^{\star \star \star \star}$ & 1.41 \\
\hline
\end{tabular}

${ }^{a}$ Cohort members with no adult offenses served as the reference category for the dependent variable (i.e., adult record type).

$p<.001^{* * *}$.

so doing, this research directly assessed several of the key assumptions of recidivism and specialization underlying current public policies regarding sex offenders and sexual offending.

The general pattern we found was that juveniles with sexually based police contacts had a high volume of non-sex contacts and a low rate of sexual recidivism during their juvenile careers, and an even lower likelihood of continuing their sexual offending behavior into adulthood. The pattern observed was consistent with regarding juvenile sex offenders as a representative group of active delinquents without any pronounced tendencies for sexual specialization as adults (Meloy, 2005; Miethe et al., 2006; Zimring et al., 2007). Overall, from the standpoint of justifying special registration for juvenile sex offenders, it is hard to imagine a more devastating pattern than the comparison between active offenders without juvenile sex records and juvenile sex offenders. Total juvenile police contacts were a more efficient predictor of future sexual danger in young adulthood than a history of juvenile sex offending or the frequency of juvenile sex offending. The best prediction of an adult sex offense was a highfrequency juvenile police contact record, whether or not any of the youthful contacts involved a sex offense.

The cohort data from Philadelphia also provided a limited but valuable opportunity to estimate the impact of sex offender registration and notification programs that either do or do not require juvenile offenders to participate. Because these cohort studies start with large and representative slices of the population, it was possible to know what percentage of a particular birth cohort's total known adult sex offenders would be in a registry if a particular law applied. Based on the results from this study, a registration provision that 
used all juvenile sex offenders would have identified a total of four males who would have an adult sex record starting at some time after age 22 in addition to 17 males who had already had sex offenses after age 18 . So, including all juvenile sex offenders would have added four future sex offenders to the registry along with 183 males who would not have sexually recidivated but must register. Thus, the marginal number of true positives contributed by juvenile records would have been four, and the rate of marginal true-to-false positives would have been 2.2 percent. Or stated differently, about two in one hundred persons added to the registry would not have been present in the predicted dangerous group because of their sexually based offending prior to age 22 , but would have been likely to offend by age 26 . Ninety-eight percent of the individuals added by juvenile records who did not also have an adult sex offense by age 22 would not have an adult sex record by age 26 .

Might this registry be effective nonetheless by providing the police with a reliable group of potential suspects? The problem here would be that 92 percent of all the adult male sex offenders were never juvenile sex offenders so the registry would be a very poor predictive tool. If this juvenile registry was used to "round up the usual suspects," 49 persons would have been needlessly predicted as sexually dangerous for every truly dangerous person so concerned, and more than 92 percent of true offenders would not have been on the registry. That appears to be a poor prediction tool for police and prosecutors and a prediction made about adult sex recidivism risk that would be wrong about 98 percent of the time.

With regard to public policy, the data available from the juvenile and young adult histories in the Second Philadelphia Birth Cohort stand in sharp contrast to the assumptions about juvenile sex offenders as outlined by Letourneau and Miner (2005; see also Garfinkle, 2003) and is present in legislation recently passed by the US House of Representatives in 2005 (House of Representatives (H.R.) 3132, 2005). That bill provides required lifetime registration for sex offenders including juveniles if convicted of acts that would have been felonies if committed by adults. Some consensual conduct is excluded for some teens, but children under 13 years of age are subject to life-long sex offender registration if their partners are under 13 years of age as well. The assumption of the legislation is that juvenile sex offending predicts high levels of sex offending as adults. The facts are that, at least in the large birth cohort data used in the current study, nine out of ten juvenile sex offenders do not sexually re-offend during the first eight years of legal adulthood and the temporal pattern of sex recidivism suggests that more than 85 percent of juvenile sex offenders will not recidivate for a sexually based offense. The Philadelphia data show that 92 percent of those cohort members who will commit sex offenses as adults had not committed any juvenile sex offenses. So the bill would falsely classify between 85 percent and 95 percent of its juvenile subjects as sexual risks for life while it would miss far more than nine out of ten of the true adult sexual risks.

Consistent with the results of Zimring et al., which employed a similar research and statistical design and relied on data from another large community-based 
cohort study, the findings in this study exposed the complete poverty of juvenile sexual behavior as a predictor of adult sexual offending. More specifically, the history or frequency of juvenile sex offending did little to assist in predicting adult sex offending over and above knowledge of the frequency of juvenile offensesespecially a high frequency of non-sex offenses. It was not merely that juvenile sex offenders were at a lower risk of adult sexual offending. They were actually less of a risk than discrete categories of active auto thieves and shoplifters. It would actually have been more efficient to make juveniles with more than five contacts who did not have any juvenile sex record register as potential sex offenders. In the end, whatever the merits of adult sex offender registration, the addition of juvenile sex offenders is more than problematic if these Philadelphia data and the Racine-based results provided by Zimring et al. provide an accurate prospectus.

At the same time, due to several data limitations, our effort is not the last word on the sex offender continuity issue. For example, the data used in this study come from one inner city (i.e., Philadelphia) during a specific historical context where the cohort members were born in the late 1950s, socialized in the 1960s and early 1970s, and reached young adulthood in the mid to late 1970s. The extent to which our results are replicable in other cities and during more recent time periods remains unknown. However, the findings from this study bear a remarkable similarity to those of Zimring et al., which provides preliminary support for the generalizability of these findings considering the salient differences in the demographics, time periods, and social contexts between Racine, WI and Philadelphia, PA. Such a replication of important substantive results is not the norm in the social sciences, especially when one considers the vast differences across the two data sources. Nevertheless, like our study, Zimring et al.'s research also relied on historical data; however, this limitation must be considered while taking into account the reality that any longitudinal study of sex offending that covers such a wide range of years will always be subject to this particular data concern (e.g., Laub \& Sampson, 2003).

It is also important to mention here that since the majority of research on sex offenders has relied on small samples of juvenile or adult incarcerated sex offenders or juvenile or adult sex offenders already in treatment, the findings from our community-based sample (like Zimring et al.'s) are much more generalizable compared to findings from prior research. Similarly, although it is difficult to determine if the true incidence of sex offending has changed over the past quarter century, it is even more difficult to assess how the criminal justice system has altered its response to sex offending. Ideally, replication of our work using offender- and victim-based self-reports would help in this regard. The Philadelphia data does tell when the police contacts resulted in official arrests; however, the data do not usually note if a police charge was later determined not to be true. On the other hand, the data did not ignore the very large number of factually accurate criminal charges that are nonetheless not followed by a conviction. Finally, the Philadelphia data did not contain 
information on exposure time, or the time that individuals were incarcerated for their crimes. Thus, to the extent that offenders-specifically sex offenderswere incapacitated for lengthy periods of time, it could have reduced their likelihood of recidivism for all types of offending. Although the collection of such data is difficult, it is important for future efforts to consider its potential impact.

In the end, our modest effort showed that the prediction of adult sex offending from juvenile sex offending is very difficult, and more generally that the assumptions underpinning current registration and notification laws are fraught with problems and should be re-considered. This prediction problem is even compounded by the poor maintenance of sex offender registries and notification systems that have been noted in prior research (see Tewksbury, 2002) along with the deleterious collateral consequences of sex offender registries including social stigmatization, loss of jobs, homes, and/or interpersonal relationships, and harassment (Mustaine, Tewksbury, \& Stengel, 2006; Tewksbury, 2004, 2005; Tewksbury \& Lees, 2006). Although these collateral consequences are not inherently unique to sex offenders and typically apply to all felons (Tewksbury \& Lees, 2006), recent research has indicated that some of these adverse outcomes may have a greater impact on sex offender reintegrationparticularly among female sex offenders (see Tewksbury, 2004, 2005; Tewksbury \& Lees, 2006).

It also appeared that juvenile sex offenders were relatively similar to juvenile non-sex offenders, except with regards to the frequency of their criminal record. Therefore, perhaps both juvenile sex offenders and juvenile non-sex offenders may benefit from the same legal interventions and treatment programs (see Letourneau \& Miner, 2005). We are certainly not arguing that juvenile sex offending should be ignored. Yet, considering the growing evidence supporting the lack of continuity of juvenile sex offending into adulthood, if these youth can be treated without unduly stigmatizing them and requiring them to register as sex offenders, then perhaps the labeling process can be avoided and successful intervention can be achieved without disrupting the youth's relations with their peers and their natural social environment.

Additionally, most data sources that link juvenile and adult sex offending do not have the necessary type and range of independent variables that mirror those expressed in contemporary criminological theories. Therefore, future research in this area should seek to obtain the necessary information with respect to key theoretical predictors that emerge from a range of criminological perspectives as this underdeveloped field of sex offender continuity moves forward. For example, insights drawn from cycle-of-violence theories (Widom, 1989) as well as developmental/life-course criminology theories that pay close attention to the involvement of a small select group of offenders in crimes of violence early, often, and throughout the life-course (Moffitt, 1993), seem like opportune avenues worth exploring. Ultimately, we hope that this study begins a dialogue for more rational decision-making about juvenile sex offenders and offending, one that is based on a body of accumulated, empirical data. 


\section{References}

Abel, G. G., Mittelman, M., \& Becker, J. V. (1985). Sex offenders: Results of assessment and recommendations for treatment. In S. Ben-Aron, S. Hucker, \& C. Webster (Eds.), Clinical criminology: Current concepts (pp. 191-205). Toronto, Canada: M \& M Graphics.

Barbaree, H. E., Hudson, S. M., \& Seto, M. C. (1993). Sexual assault in society: The role of the juvenile offender. In H. E. Barbaree, W. L. Marshall, \& S. M. Hudson (Eds.), The juvenile sex offender (pp. 1-24). New York: Guilford Press.

Becker, J. V., Cunningham-Rathner, J., \& Kaplan, M. S. (1986). Adolescent sexual offenders: Demographics, criminal and sexual histories, and recommendations for reducing future offenses. Journal of Interpersonal Violence, 1, 431-445.

Burton, D. L. (2000). Were adolescent sexual offenders children with sexual behavior problems? Sexual Abuse: A Journal of Research and Treatment, 12, 37-48.

Doren, D. M. (1998). Recidivism base rates, prediction of sex offender recidivism, and the "sexual predator" commitment laws. Behavioral Sciences and the Law, 16, 97-114.

Field, A. P. (2005). Discovering statistics using SPSS (2nd ed.). London: Sage.

Garfinkle, E. (2003). Coming of age in America: The misapplication of sex-offender registries and community-notification laws to juveniles. California Law Review, 91, 163-208.

Groth, N, Longo, R., \& McFadin, J. (1982). Undetected recidivism among rapists and child molesters. Crime and Delinquency, 28, 450-458.

Hagan, M. P., \& Gust-Brey, K. L. (1999). A ten-year longitudinal study of adolescent rapists upon return to the community. International Journal of Offender Therapy and Comparative Criminology, 43, 448-458.

Hindelang, M. J., Hirschi, T., \& Weis, J. G. (1981). Measuring delinquency. Beverly Hills, CA: Sage.

House of Representatives (H.R.) 3132. (2005). Children's Safety Act of 2005.

Langström, N. (2002). Long-term follow-up of criminal recidivism in young sex offenders: Temporal patterns and risk factors. Psychology, Crime, and Law, 8, 41-58.

Langström, N., \& Grann, M. (2000). Risk for criminal recidivism among young sex offenders. Journal of Interpersonal Violence, 25, 856-872.

Laub, J. H., \& Sampson, R. J. (2003). Shared beginnings, divergent lives: Delinquent boys to age 70. Cambridge, MA: Harvard University Press.

Letourneau, E. J., \& Miner, M. H. (2005). Juvenile sex offenders: A case against the legal and clinical status quo. Sexual Abuse: A Journal of Research and Treatment, 17, 293-312.

Meloy, M. L. (2005). The sex offender next door: An analysis of recidivism, risk factors, and deterrence of sex offenders on probation. Criminal Justice Policy Review, 16, 211-236.

Miethe, T. D., Olson, J., \& Mitchell, O. (2006). Specialization and persistence in the arrest histories of sex offenders: A comparative analysis of alternative measures and offense types. Journal of Research in Crime and Delinquency, 43, 204-229.

Milloy, C. D. (1994). A comparative study of juvenile sex offenders and nonsex offenders. Olympia, WA: Washington State Institute for Public Policy.

Miner, M. H. (2002). Factors associated with recidivism in juveniles: An analysis of serious juvenile sex offenders. Journal of Research in Crime and Delinquency, 39, 421-436.

Miner, M. H. (2007). The fallacy of juvenile sex offender risk. Criminology and Public Policy, 6, 565-571.

Miner, M. H., Siekert, G. P., \& Ackland, M. A. (1997). Evaluation: Juvenile sex offender treatment program, Minnesota Correctional Facility-Sauk Centre. Minneapolis, MN: University of Minnesota, Department of Family Practice and Community Health, Program in Human Sexuality. 
Moffitt, T. E. (1993). Life-course-persistent and adolescence-limited antisocial behavior: A developmental taxonomy. Psychological Review, 100, 674-701.

Mustaine, E., Tewksbury, R., \& Stengel, K. (2006). Residential location and mobility of registered sex offenders. Deviant Behavior, 27, 177-192.

Nisbet, I. A., Wilson, P. H., \& Smallbone, S. W. (2004). A prospective longitudinal study of sexual recidivism among adolescent sex offenders. Sexual Abuse: A Journal of Research and Treatment, 16, 223-234.

Piquero, A. R., Farrington, D. P., \& Blumstein, A. (2003). The criminal career paradigm. In M. Tonry (Ed.), Crime and justice: A review of research, volume 30. Chicago: University of Chicago Press.

Rasmussen, L. A. (1999). Factors related to recidivism among juvenile sexual offenders. Sexual Abuse: A Journal of Research and Treatment, 11, 69-85.

Rubinstein, M., Yeager, C. A. Goodstein, C., \& Lewis, D. O. (1993). Sexually assaultive male juveniles: A follow-up. American Journal of Psychiatry, 150, 262-265.

Ryan, G. (1998). What is so special about specialized treatment. Journal of Interpersonal Violence, 13, 647-652.

Ryan, G. (1999). Treatment of sexually abusive youth. The evolving consensus. Journal of Interpersonal Violence, 14, 422-436.

Sample, L. L., \& Bray, T. M. (2003). Are sex offenders dangerous? Criminology \& Public Policy, 3, 59-82.

Sample, L. L., \& Bray, T. M. (2006). Are sex offenders different? An examination of rearrest patterns. Criminal Justice Policy Review, 17, 83-102.

Sipe, R., Jensen, E. L., \& Everett, R. S. (1998). Adolescent sexual offenders grown up. Criminal Justice and Behavior, 25, 109-124.

Terry, K. J. (2005). Sexual offenses and offenders: Theory, practice, and policy. Belmont, CA: Wadsworth.

Tewksbury, R. (2002). Validity and utility of the Kentucky sex offender registry. Federal Probation, 66, 21-26.

Tewksbury, R. (2004). Experiences and attitudes of female sex offenders. Federal Probation, 68, 30-33.

Tewksbury, R. (2005). Collateral consequences of sex offender registration. Journal of Contemporary Criminal Justice, 21, 67-81.

Tewksbury, R., \& Lees, M. (2006). Perceptions of sex offender registration: Collateral consequences and community experiences. Sociological Spectrum, 26, 309-334.

Thornberry, T. P., \& Krohn, M. D. (2003). The self-report method for measuring delinquency and crime. In D. Duffee (Ed.), Criminal justice 2000, Volume 4, measurement and analysis of crime. Washington, DC: National Institute of Justice.

Tracy, P. E., \& Kempf-Leonard, K. (1996). Continuity and discontinuity in criminal careers. New York: Plenum.

Tracy, P. E., Wolfgang, M. E., \& Figlio, R. M. (1990). Delinquency careers in two birth cohorts. Chicago: University of Chicago Press.

Vandiver, D. M. (2006). A prospective analysis of juvenile male sex offenders: Characteristics and recidivism rates as adults. Journal of Interpersonal Violence, 21, 673-688.

Van Wijk, A., Vermeiren, R., Loeber, R., Hart-Kerkhoffs, L., Doreleijers, T., \& Bullens, R. (2006). Juvenile sex offenders compared to non-sex offenders: A review of the literature 1995-2005. Trauma, Violence, and Abuse, 7, 227-243.

Waite, D., Keller, A., MCGarvey, E. L., Wieckowski, E., Pinkerton, R., \& Brown, G. L. (2005). Juvenile sex offender re-arrest rates for sexual, violent non-sexual, and property crimes: A ten-year follow-up. Sexual Abuse: A Journal of Research and Treatment, 17, 313-331.

Weinrott, M. R., Riggan, M., \& Frothingham, S. (1997). Reducing deviant arousal in juvenile sex offenders using vicarious sensitization. Journal of Interpersonal Violence, 12, 704-728. 
Widom, C. S. (1989). The cycle of violence. Science, 244, 160-166.

Wolfgang, M. E., Figlio, R. M., \& Sellin, T. (1972). Delinquency in a birth cohort. Chicago: University of Chicago Press.

Wolfgang, M. E., Thornberry, T. P., \& Figtio, R. M. (1987). From boy to man, from delinquency to crime. Chicago: University of Chicago Press.

Worling, J. R., \& Curwen, T. (2000). Adolescent sexual offender recidivism: Success of specialized treatment and implications for risk prediction. Child Abuse and Neglect, 24, 965-982.

Zimring, F. E. (2004). An American travesty: Legal responses to adolescent sexual offending. Chicago: University of Chicago Press.

Zimring, F. E., Piquero, A. R., \& Jennings, W. G. (2007). Sexual delinquency in Racine: Does early sex offending predict later sex offending in youth and young adulthood. Criminology and Public Policy, 6, 507-534. 